\title{
Fictionalism and Meinongianism
}

\author{
(Ficcionalismo y Meinongianismo)
}

\author{
Nathaniel GAN* \\ University of Sydney
}

\begin{abstract}
Fictionalism about a kind of disputed object is often motivated by the fact that the view interprets discourse about those objects literally without an ontological commitment to them. This paper argues that this motivation is inadequate because some viable alternatives to fictionalism have similar attractions. Meinongianism - the view that there are true statements about non-existent objects-is one such view. Meinongianism bears significant similarity to fictionalism, so intuitive doubts about its viability are difficult to sustain for fictionalists. Moreover, Meinongianism avoids some of fictionalism's weaknesses, thus it is even preferable to fictionalism in some respects.
\end{abstract}

KEYWORDS: Ontological debates; fictionalism; Meinongianism; mathematics.

RESUMEN: El ficcionalismo acerca de un tipo de objeto que está cuestionado, en cuestión está a menudo motivado por el hecho de que se interpreta el discurso sobre esos objetos literalmente, esto es, sin ningún compromiso ontológico sobre ellos. Este artículo defiende que dicha motivación es inadecuada porque algunas alternativas viables al ficcionalismo tienen atractivos semejantes. El meinongianismo-la visión según la cual hay enunciados verdaderos con respecto a objetos no existentes - es una de esas aproximaciones. El meinongiansmo tiene semejanzas significativas con el ficcionalismo, con lo cual las dudas intuitivas sobre su viabilidad son difíciles de mantener para los ficcionalistas. Además, el meinongianismo evita algunas de las debilidades del ficcionalismo, con lo cual, en algunos aspectos es preferible al ficcionalismo.

PALABRAS CLAVE: debates ontológicos; ficcionalismo; meinongianismo; matemáticas.

* Correspondence to: Nathaniel Gan. Department of Philosophy, School of Philosophical and Historical Inquiry, A14 Main Quadrangle, University of Sydney (NSW 2006, Australia) - nat_gan@hotmail.com - https://orcid.org/0000-0002-9463-7955

How to cite: Gan, Nathaniel. (2021). "Fictionalism and Meinongianism»; Theoria. An International Journal for Theory, History and Foundations of Science, 36(1), 49-62. (https://doi.org/10.1387/theoria.21727).

Received: 2020, May 16; Final version: 2020, October 24.

ISSN 0495-4548 - eISSN 2171-679X / (C) 2021 UPV/EHU 
In debates over ontology, realism typically affords a straightforward account of the relevant discourse. If a kind of object is held to exist, then statements about those objects can be interpreted literally and given a referential semantics. But in some cases, an ontological commitment may incur significant costs. Realists might face challenges, say, in giving a plausible epistemology or an adequate identification of the objects in question. In such instances, it is sometimes suggested that we adopt a fictionalist view of the disputed objects, which seeks to interpret discourse about those objects literally without affirming their existence. An attractive feature of fictionalism is that it seems to offer the benefits of realism without the corresponding costs.

This paper will argue that in many instances, these considerations insufficiently motivate fictionalism, because at least one other view bears similar attractions to fictionalism: Meinongianism. Meinongianism about a kind of object is the view that those objects do not exist, but there are true sentences about them. It will be argued that Meinongianism is a viable alternative to fictionalism that is even preferable to fictionalism in some respects. While this does not mean that fictionalist views fail to deliver their purported benefits, nor even that they are suboptimal views, the presence of such an alternative suggests that antirealists should not be too quick to adopt fictionalism, at least not before considering all their options.

$\$ 1$ lays out the components of the fictionalist view and explains its attractions. $\$ 2$ introduces Meinongianism and $\$ 3$ addresses intuitive concerns that potentially hinder us from seeing Meinongianism as a possible alternative to fictionalism. $\$ 4$ argues that Meinongianism has some of the same attractions as fictionalism and, in fact, some advantages over fictionalism.

\section{Fictionalism}

As an illustration of how fictionalism might be attractive, consider the case of mathematics. Platonism affords significant benefits in its account of mathematical discourse. First, Platonists can interpret mathematical discourse literally. If mathematical objects are admitted into our ontology, then ' $2+2=4$ ' can be interpreted as a statement about the objects 2 and 4. Second, Platonists can apply a referential semantics to mathematical statements, thereby yielding an overall semantics that is uniform between mathematical discourse and ordinary discourse. Third, Platonists can easily account for the affirmations (and denials) made in mathematical discourse. Since Platonists say that there are objective facts of the matter regarding mathematical truth, they can make sense of the affirmations in our mathematical discourse as attempts to track truth.

But Platonism also has its costs. For one, Platonists posit the existence of mathematical objects, and this puts them at a disadvantage compared to nominalists regarding parsimony. If nominalists can account for all the same phenomena as Platonists, then considerations of parsimony would tip the scales in favour of nominalism. Furthermore, the abstractness of mathematical objects is usually thought to make it challenging for Platonists to give a plausible account of mathematical knowledge (Benacerraf, 1973; Field, 1989) or a precise identification of mathematical objects (Benacerraf, 1965, 1996). These weaknesses of Platonism show that the view might, in some respects, be at a disadvantage compared to nominalism. 
One can gain the advantages of nominalism (that is, avoid the costs of a Platonist ontology) while recovering some benefits of Platonism by adopting an error theory about mathematics. Mathematical error theorists hold that mathematical statements are to be interpreted literally as purporting reference to mathematical objects, and that referential truth conditions are to be applied to such statements. Therefore, a mathematical error theory has some of the benefits of Platonism described earlier. At the same time, mathematical error theorists do not affirm the existence of mathematical objects, so they avoid the costs of an ontological commitment thereto. It seems to follow from these two claims that mathematical error theorists do not affirm most mathematical statements. Indeed, error theories admit the possibility that most mathematical statements are false, and the only true mathematical statements are those that follow from the non-existence of mathematical objects (such as universal statements, which are vacuously true, or negative existentials).

Error theories raise questions about the affirmations made in our mathematical discourse. If almost all mathematical statements may be false, why do mathematicians affirm many (but not all) mathematical statements? Mathematical fictionalism is an attempt to accommodate the affirmations made in our mathematical discourse while maintaining an error-theoretic view. In addition to withholding affirmation from the existence of mathematical objects, and hence from almost all mathematical statements, mathematical fictionalists also say that there is a weaker sense in which mathematical statements are true. Namely, they say that some mathematical statements are acceptable-true according to the theory adopted in our mathematical discourse (which theory might not be true). Mathematical fictionalists account for the affirmations made in mathematical discourse by saying that these affirmations are intended to track acceptability rather than truth. ${ }^{1}$ In this way, mathematical fictionalism seems to afford the benefits of both nominalism and Platonism.

Mathematical fictionalism seems to be a rather popular form of nominalism, held by Otávio Bueno (2009), Hartry Field (1989), and Mary Leng (2005, 2010), among others. The features just observed are often presented as fictionalism's main attractions. Bueno, for instance, says that a reason to consider mathematical fictionalism is that it has all the benefits of Platonism without the corresponding costs ... [and] has none of the costs of nominalism, while keeping all of its benefits' (Bueno, 2009, p. 63; emphasis original). Mark Balaguer goes further, saying that mathematical fictionalism is the best form of nominalism, for some of the reasons just observed:

I think fictionalism is the best version of [nominalism] ... whereas fictionalism interprets our mathematical theories in a very standard, straightforward, face-value way, other versions of

1 All mathematical fictionalists agree that a mathematical statement $S$ is acceptable just in case $S$ is true according to the accepted theory of mathematics, but they differ on how precisely the claims made in mathematical discourse are to be understood in light of this analysis. Some fictionalists say that we mean that $S$ is true according to the theory of mathematics when we claim that $S$ is true. Others say that we make a literally false claim when we say that $S$ is true, and should say instead that $S$ is true according to the theory of mathematics if we want to speak truly. See Burgess $(1983,2004)$, Burgess \& Rosen (1997). For present purposes, mathematical fictionalism will be understood in the latter sense. The former view has several disadvantages. Besides being a rather implausible view about what our mathematical claims mean (Liggins, 2010; Reynolds, 2009; Stanley, 2001), it also does not take mathematical discourse literally, which undermines part of the motivation for fictionalism. 
anti-realism - such as deductivism, formalism, and conventionalism-advocate controversial, non-standard, non-face-value interpretations of mathematics that seem to fly in the face of actual mathematical practice. (Balaguer, 1998, p. 102)

Fictionalism has also been suggested as an approach to moral properties (Joyce, 2001; Kalderon, 2005; Nolan et al., 2005), fictional characters (Brock, 2002, 2015; Kripke, 1973; Lewis, 1978), concrete possible worlds (Divers, 1999; Rosen, 1990, 1995), time (Baron et al., 2019), parts (Schaffer, 2007), and composite objects (Rosen \& Dorr, 2002), among other things. Many of these fictionalist views also seem to be motivated along the above lines. In general, fictionalism about a kind of disputed object is characterised by four claims:

(i) We are not ontologically committed to the objects in question. ${ }^{2}$

(ii) Statements about the objects in question are to be taken literally and given a referential semantics.

(iii) Most statements in the relevant discourse may not be true. It might be that the only true statements about the objects in question are those that follow from their non-existence.

(iv) A statement about the objects in question is affirmed in our discourse just in case it is taken to be true according to the accepted theory of the relevant domain.

(i) implies that fictionalism avoids the costs of a realist ontology. (ii) tells us how statements in the relevant discourse are to be interpreted under fictionalism. From (i) and (ii), it is usually thought that (iii) follows, which says that fictionalism is an error theory. (iii) implies that fictionalists owe an account of the affirmations made in the relevant discourse, and (iv) is an attempt to give such an account. (ii) and (iv) together imply that the fictionalist account of the relevant discourse is, in several ways, as straightforward as the realist one. Consequently, if (i)-(iv) can consistently be held in conjunction, then fictionalism would be an anti-realist view that recovers the semantic benefits of realism.

This is certainly an attractive feature of fictionalism. However, it will be argued in the remainder of this paper, these considerations may be insufficient for motivating the view. For, at least one other view has the same attractions, and so presents a viable alternative to fictionalism.

\section{Meinongianism}

It is typically thought that (i) and (ii) together entail (iii). If a statement purports reference to an entity, then it seems natural to think that a necessary condition for that statement to be true is that the entity exist. Meinongianism is a view that denies this. Roughly, Meinon-

2 Many fictionalists present their view as a form of anti-realism, but it is perhaps unclear if they merely do not affirm the existence of the objects in question (which leaves open the possibility of deflationism) or if they deny the existence of those objects. Some fictionalists make the even weaker claim that we have no reason either to affirm or to deny the existence of the target objects; that is, they say that we should be agnostic about the existence of those objects (e.g. Bueno, 2009). In this paper, fictionalism will be understood more broadly as a view that simply denies an ontological commitment to the objects in question. 
gianism about a kind of disputed object holds that those objects do not exist, but can nevertheless be the referents of terms in true sentences. On these grounds, Meinongians affirm (i) and (ii) about the objects in question without holding an error theory.

More precisely: given a disputed entity whose name is $a$, the theory we have adopted in the corresponding domain quantifies over a class of objects; let $D$ denote this class. It is usually assumed that the following are coextensive: $D$, the class of all objects in $D$ that exist, and the range of the existential quantifier $\exists$ in $D$. Then, it is inferred from the truth of a property-ascription sentence $F a$ that the referent of $a$ exists (and that it witnesses $\exists x F x$ ), because $F a$ entails that the referent of $a$ is in $F$, and a fortiori in $D$. Consequently, if the disputed object does not exist, then $a$ does not refer and $F a$ is false.

But if the initial assumption is denied, then this last conditional is not generally true. Under a Meinongian view of the referent of $a$, the range of $\exists$ coincides with the set of objects that exist in $\mathcal{D}$, but this set is a proper subset of $\mathcal{D}$ that excludes the referent of $a$. Consequently, $\exists$ no longer ranges over $D$ and $F a$ no longer entails that the referent of $a$ witnesses $\exists x F x$. It also no longer follows from $F a$ that the referent of $a$ exists, only that $a$ refers and that its referent is in $D$. So even if the disputed object does not exist, it does not follow that $\mathrm{Fa}$ is false. ${ }^{3}$

In general, Meinongians about a kind of disputed object hold that

(i) We are not ontologically committed to the objects in question. ${ }^{4}$

(ii) Statements about the objects in question are to be taken literally and given a referential semantics.

(iii*) Some statements about the objects in question are true in virtue of their referents.

$\left(\mathrm{iv}^{*}\right)$ A statement about the objects in question is affirmed in our discourse just in case it is thought to be true.

Meinongianism was originally defended by Alexius Meinong (1904), and the view has recently been developed and defended by Francesco Berto (2013), Otávio Bueno (2009), 5 Terence Parsons (1980), Graham Priest (2005), and Edward Zalta (1988), among others.

3 Another possible way of denying the inference from $F a$ to the existence of the referent of $a$ is to maintain that $\exists$ ranges over all of $\mathcal{D}$ while denying that all objects within the range of $\exists$ exist. Some Meinongians have explored this possible explication of their view (Zalta, 1983). Azzouni (2004) has also defended a view along these lines, though he distinguishes his view from Meinongianism as typically conceived. See Bueno \& Zalta (2005) for a comparison between Azzouni's and Zalta's views. Thanks to an anonymous referee for noting this point.

4 Meinongianism is typically presented as holding only that there could be true statements about nonexistent objects, not that there actually are such statements. But for the purposes of evaluating views against the costs and benefits of realism and anti-realism, Meinongianism would be indistinguishable from realism if it did not deny an ontological commitment to the objects in question-it would also bear the costs of a realist ontology. So, Meinongianism will here be understood as an anti-realist view.

5 Bueno discusses two views, both of which he calls 'fictionalism'. The first view, called 'empirical fictionalism', closely resembles fictionalism as characterised by (i)-(iv) earlier (except for the difference observed in n.2). The second view, though also called 'fictionalism', in fact looks more similar to Meinongianism as presented here. It uses a characterisation principle for a domain of (possibly) nonexistent objects, gives an account of reference to those objects, and affirms the truth of some statements about those objects. 


\section{Intuitive concerns}

Meinongianism is sometimes thought to be an unintuitive view with unacceptably strange consequences. In this section, such concerns regarding its viability will be addressed. It will be argued that Meinongianism is in fact a viable view, and that there are reasons to consider it a possible alternative to fictionalism.

One possible reason that Meinongianism might seem problematic is that it might be thought to involve an unacceptably profligate ontology. A claim sometimes attributed to Meinong, and put forward by the early Bertrand Russell (1903), is that non-existent objects in the target domain nevertheless have some form of existence, sometimes called 'being' or 'subsistence' (e.g. Quine, 1948; Russell, 1905a). But although this is compatible with the broad Meinongian idea that there are true sentences about non-existent (in some sense) objects, ${ }^{6}$ Meinongians are not committed to this claim. Indeed, some contemporary Meinongians have sought to clarify that they do not take the objects in question to exist in any sense at all (e.g. Priest, 2006, p. 14). The fact that such objects are in the domain, under contemporary views, only indicates their availability for reference and property ascription. Taking Meinongianism in this latter sense, the view does not incur an unacceptable ontological cost.

A second possible doubt regarding Meinongianism concerns the characterisation of the domain of non-existent objects. In particular, Meinongians owe an account of which objects are in the domain, what properties those objects have, and what principles govern their identity. To see why these issues might raise difficulties, consider a naïve version of Meinongianism, which holds that for every given set of properties there is some object that exactly bears those properties. This view was criticised by Bertrand Russell (1905a, 1905b, 1907) and Quine (1948) on several counts. Under the naïve Meinongian view, the property of existence can be added to any combination of properties to yield existent objects that are incomplete (e.g. an existent object that is red and nothing else), inconsistent (e.g. an existent round square), or that straightforwardly disagrees with empirical observation (e.g. an existent golden mountain on Earth). Moreover, it is unclear how an adequate criterion of identity can be given for the domain of non-existent objects or how we can account for reference to those objects. It might be thought, by those who consider Meinongianism problematic, that similar problems arise for all Meinongian views.

But such worries are unfounded. While these considerations may well be decisive against naïve Meinongianism, more sophisticated forms of Meinongianism can address these issues by characterising the objects in $D$ more carefully. Some Meinongians use a characterisation principle that quantifies over a restricted set of properties, ${ }^{7}$ or distinguish various ways in which objects might bear properties, ${ }^{8}$ or situate the objects in question across modal space. ${ }^{9}$ These forms of Meinongianism, at least according to their proponents,

6 It has been observed that some contemporary forms of Meinongianism are significantly similar to realist views about abstract objects (Linsky \& Zalta, 1995).

7 See Jacquette (1989, 1996, 2001), Parsons (1978, 1979, 1980, 1982), Routley (1966, 1980, 1982, 2003) and Sendlak (2013)

8 See Bueno and Zalta (2017), Castañeda (1972, 1975), Linsky \& Zalta (2006), Rapaport (1978), and Zalta $(1983,1988,2000)$.

9 See Berto (2008, 2011, 2013), Berto \& Priest (2014), and Priest (2003, 2005). 
avoid the above problems that arise for naïve Meinongianism. More importantly (for present purposes), the issue of giving a characterisation principle raises a serious challenge only for views that are Meinongian across the board-that is, views under which every kind of object can be the non-existent referent of a true sentence. Of such views, it seems natural to ask about the limits of $\mathcal{D}$ or the properties that may be ascribed to objects therein. But when it comes to Meinongianism about a particular kind of object, which holds only that the objects in question can be non-existent referents of terms in true sentences, questions about the characterisation of $\mathcal{D}$ have forthcoming answers. ${ }^{10}$ In most domains, we seem to have adopted a theory on which our judgments are based, such as the theories generated by the standard axioms of mathematics, or our best scientific theories, or the consensus between our moral judgments. In such cases, Meinongians about a kind of object can take $D$ to be characterised by our adopted theory of the corresponding domain. That is, an object is in $\mathcal{D}$ just in case the theory quantifies over that object, objects in $\mathcal{D}$ bear properties according to property ascriptions in the theory, and pairs of objects are identical just in case the theory identifies them. Then, insofar as our theory in a domain is consistent or empirically adequate (etc.), $D$ will be as well. ${ }^{11}$ Therefore, Meinongians have several possible ways of meeting the usual challenges that arise regarding characterisation.

Yet another possible criticism of Meinongianism is that even with the aforementioned issues resolved, the view nevertheless remains unacceptably unintuitive. A comparison of Meinongianism and fictionalism, however, reveals that the two views are in fact rather similar, which suggests that intuitive worries about Meinongianism are hard to sustain for fictionalists.

To see why this is the case, consider again the case of mathematics. Setting aside Meinongianism for the moment, consider a Platonist view that Mark Balaguer calls fullblooded Platonism (Balaguer 1995, 1998, 2017). As a form of Platonism, full-blooded Platonism holds that mathematical objects exist. In fact, it holds that every possible mathematical object exists, and that any consistent mathematical theory is true of some mathematical object. So all it takes for a mathematical statement to be true, under this view, is for it to be part of a possible - and therefore true-theory. And, a statement is affirmed in mathematical practice just in case it is true according to the (true) theory we happened to have adopted.

It has been observed that full-blooded Platonism and mathematical fictionalism are similar in several important respects (Balaguer, 1998; Leng, 2009):

1. Literal interpretation. Both views interpret mathematical statements literally as purporting reference to mathematical objects.

10 To be sure, if there is a true sentence $F a$ such that the referent of $a$ does not exist, then in general, $F a \vDash \exists x F x$ is not formally valid because it is logically possible for the extension of $F$ to exceed the range of $\exists$. Hence, Meinongianism about a particular object implies, across-the-board, the broad Meinongian idea that non-existent objects can be the referents of terms in true sentences. Nevertheless, Meinongians about a particular kind of object can hold that in domains other than the target domain, $D$ actually coincides with the range of $\exists$, so that every instance of $F a \vDash \exists x F x$ is valid (in virtue of meaning) whenever $a$ is an object not of the target kind. Hence, the question of characterising $D$ arises only for the target domain.

11 If the theory in question is not categorical, $D$ may not be uniquely determined by the theory. Nevertheless, so long as $\mathcal{D}$ is chosen to be any model of the theory in question, $D$ will inherit the properties of consistency and empirical adequacy (etc.). Thanks to an anonymous referee for noting this point. 
2. Referential truth conditions. Both views say that a mathematical statement is true just in case it accurately describes the properties borne by the mathematical objects to which it refers.

3. Acceptability conditions. Both views say that a mathematical statement is acceptable in mathematical discourse just in case it is true according to the theory that has been adopted.

4. Mathematical knowledge. Both views say that knowledge of which mathematical statements are acceptable does not require epistemic access to abstract objects, but consists only in knowledge of what follows from the axioms we have adopted.

5. Axioms. Both views say that the mathematical theory used in our discourse is generated by the axioms we have adopted, but there is nothing metaphysically special about these axioms or the resulting theory. That is, neither view claims that the current axioms of mathematics are true to the exclusion of other consistent sets of axioms.

In fact, the only substantive differences between full-blooded Platonism and mathematical fictionalism lie in their pronouncements regarding the truth of mathematical statements and the existence of mathematical objects. Apart from this difference, whatever fullblooded Platonists say is true about the mathematical object that satisfies a mathematical theory, mathematical fictionalists say is true within the corresponding fictional theory.

In view of the similarities between these two views, it seems that mathematical fictionalists have little grounds on which to raise intuitive doubts about full-blooded Platonism. For, the full-blooded Platonist's view on the semantics of mathematical discourse, the acceptability of mathematical statements, the epistemology of mathematical facts, and the justificatory status of mathematical axioms are in fact the fictionalist's own. Any disagreement between the two views comes down to disagreements over mathematical ontology and alethiology; and while fictionalists may hold that full-blooded Platonism is mistaken on these issues, on neither count does the Platonist view seem unacceptably unintuitive.

In light of this, it seems that mathematical fictionalists do not have grounds on which to raise intuitive doubts about mathematical Meinongianism either. For a start, mathematical Meinongians can affirms all the points on which full-blooded Platonism and mathematical fictionalism agree. Literal interpretation and Referential truth conditions follow from claim (ii); Acceptability conditions follows from claim (iv*). And, as noted above, mathematical Meinongians can take the domain of mathematical objects to be characterised by our theory of mathematics. Under such a view, we have Mathematical knowledge: knowledge of which mathematical statements are acceptable (and, in fact, true) does not require epistemic access to abstract objects, but is simply knowledge of the logical consequences of our axioms. Mathematical Meinongians can also agree with full-blooded Platonists and mathematical fictionalists that there is nothing metaphysically privileged about our adopted theory. If the domain of mathematical objects is characterised by our theory of mathematics, then although the theory generated by one set of axioms may turn out to be more useful than alternatives (which may explain why we adopted a particular theory ${ }^{12}$ ), we would still not have ended up with a false theory had we adopted another set of axioms. Rather, we would simply have had a theory that is true about a different domain of objects.

12 See, for example, Yablo (2005) for a fictionalist account of how a theory can come to be adopted. 
Hence, mathematical Meinongians can agree to Axioms. Therefore, mathematical Meinongianism, at least in some forms, is similar to mathematical fictionalism in much the same way as is full-blooded Platonism. ${ }^{13}$

In fact, mathematical Meinongianism is in some respects more similar to mathematical fictionalism than is full-blooded Platonism. The former two views, but not the latter, hold that mathematical objects do not exist. So, the mathematical Meinongian's view on semantics, acceptability, epistemology, axioms, and ontology align with those of mathematical fictionalism. Differences between the two views show up when we consider mathematical alethiology, but even on this issue, the mathematical Meinongian view is nothing other than the full-blooded Platonist's. Therefore, if mathematical fictionalists should consider full-blooded Platonism a viable alternative to their view (and it seems they should), then $a$ fortiori mathematical Meinongianism should be taken seriously as an option as well.

Nothing has been said so far about whether full-blooded Platonism and mathematical Meinongianism present genuine alternatives to mathematical fictionalism. Perhaps there is nothing beyond the points of agreement identified that might bear upon mathematical ontology and alethiology. In this case, the agreement between the three views would imply that they are on a par with each other, with nothing to adjudicate between them. ${ }^{14}$ Perhaps we might even say that the three views are merely notational variants of each other, and any differences between them regarding ontology and alethiology are simply artefacts of the way the views are presented. On the other hand, there may be substantive differences between the views. Perhaps there are important disagreements between the three views over, for instance, the modal status of mathematical ontology and alethiology. ${ }^{15} \mathrm{Or}$, there might be factors that tip the scales in the disagreements over ontology and alethiology when other things are equal. For instance, it might be thought that mathematical fictionalism and mathematical Meinongianism are superior to full-blooded Platonism on account of their more parsimonious ontology, so that the agreement between the three views shows that we should limit our consideration only to the first two. But regardless of whether the three views differ significantly from each other, the point of what has been argued thus far still stands: mathematical Meinongianism is worth considering as an alternative to mathematical fictionalism; and insofar as there are genuine disputes to be had over mathematical alethiology, this alternative is a genuine one.

13 Indeed, some have observed similarities between mathematical Meinongianism and the other two views. See Colyvan \& Zalta (1998) and Berto (2011).

${ }_{14}$ Balaguer (1998) argues, along these lines, that there is no fact of the matter as to whether mathematical objects exist because there is no way to decide between full-blooded Platonism and mathematical fictionalism. Extending his reasoning might give the conclusion that there is no fact of the matter as to whether mathematical statements are true.

15 Priest (2005) observes two differences between full-blooded Platonism and mathematical Meinongianism: the former limits our consideration to consistent mathematical theories and says that whatever mathematical objects exist do so necessarily; the latter includes inconsistent mathematical theories and says that there might have been different mathematical objects in the domain (the first of these differences can be eliminated by considering a more generous version of full-blooded Platonism that admits impossible entities-see Beall (1999)). In these respects, mathematical fictionalism seems closer to mathematical Meinongianism than full-blooded Platonism, so perhaps these observations might not help to resolve the dispute between the former two views. 
In the general case, if fictionalists are to raise criticisms against Meinongianism, it seems that these criticisms will have to be directed at the Meinongian view of the relevant alethiology. But there seems to be little grounds for saying that the Meinongian view on this issue is unacceptably unintuitive. Indeed, $\$ 4$ will argue that the Meinongian view of alethiology in the target domain is in some ways superior to the fictionalist view. Also, the fictionalist view is typically motivated by features other than its alethiology, as may be observed from $\$ 1$. So in most cases, the reasons that have thus far been suggested inadequately motivate fictionalism.

\section{Advantages over fictionalism}

$\$ 3$ argued that Meinongianism presents a viable alternative to fictionalism. This section will argue for a yet stronger claim: there are ways in which Meinongianism is a more attractive alternative to fictionalism.

To begin with, Meinongianism has the attractions of fictionalism described in $\$ 1$. Meinongianism interprets statements in the relevant discourse literally and gives them a referential semantics, so this view yields a uniform overall semantics without the need to reinterpret discourse. Moreover, Meinongians can make sense of our affirmations in the relevant discourse. They, like realists, say that a statement in the discourse is acceptable just in case it is true. At the same time, Meinongians deny the existence of the target objects, thus they avoid the costs of a realist ontology. Therefore, Meinongianism, like fictionalism, has the benefits of realism without its costs.

Next, fictionalism, despite its considerable strengths, has some weaknesses. Although the fictionalist account of discourse is as straightforward as the realists' in many respects, there are also a few ways in which the former is inferior. In particular, fictionalists do not take the truth of statements in the target discourse at face value, as realists do. Realists about a kind of object say that our adopted theory about those objects, which is affirmed in the relevant discourse, is (approximately) true. The corresponding fictionalist view, however, does not endorse the literal truth of this theory. Also, fictionalism holds a somewhat atypical view of what it would take for statements about the target objects to be acceptable. In ordinary discourse, we usually affirm a statement just in case we think it is true simpliciter. But according to fictionalism, we affirm a statement about the target objects just in case we think it is true according to a theory that might be, nonetheless, false. Therefore, while fictionalists apply uniform truth conditions to statements in the relevant discourse and ordinary discourse, it does not apply uniform acceptability conditions. These observations are by no means decisive arguments against fictionalism. Indeed, some fictionalists have argued that there are good reasons not to take truth at face-value (e.g. Leng, 2005, 2018), or to use non-uniform acceptability conditions (e.g. van Fraassen, 1980; Yablo, 2009) in some domains. Nevertheless, these features of fictionalism imply that its treatment of the relevant discourse is less straightforward than that given by the corresponding realist view.

A challenge also potentially arises for fictionalists in cases where our practices regarding the target objects go beyond our discourse. For instance, we employ mathematics not only in our mathematical discourse, but also in some aspects of scientific practice, which raises a question regarding how mathematics can be applicable to science. Platonists have 
an advantage over nominalists here, because they can appeal to the truth of mathematics and the existence of mathematical objects when accounting for the applicability of mathematics. Nominalists face a challenge, because it might be unclear (at least initially) how mathematics can play its role in science if no mathematical objects bear properties according to the mathematical theories that contribute to the success of science. But this challenge for nominalists is yet more difficult for mathematical fictionalists, because the applicability of mathematics to science would seem yet more mysterious if the mathematics used in our best scientific theories is not even true. Indeed, some argue that the applicability of mathematics to science justifies a belief in the truth of mathematical statements, but do not endorse a further inference to the existence of mathematical objects (Hellman, 1989; Putnam, 1979).

Our practices concerning some other kinds of disputed objects also go beyond our discourse. It has been suggested that objective moral properties not only serve to explain our moral judgments (Majors, 2003; Sturgeon, 1988) but also make deliberation possible (Enoch, 2011), and that scientific objects play an explanatory role in our accounts of scientific phenomena (Putnam, 1979; Smart, 1963). These aspects of our practices lend support to realists about the respective objects while putting pressure on anti-realists, who will have to make sense of these practices without assuming the existence of those objects. And, the challenge will be yet greater for fictionalists, who have less theoretical resources, compared to other anti-realists, to which they can appeal when accounting for the relevant practices. Again, this problem might not be insurmountable for fictionalists. In some cases, it might be possible to give a satisfactory account of the relevant practices without appealing to the truth of statements about the objects in question (e.g. Leng, 2012; Liggins, 2012), and it might even be possible to account for those practices without making apparent reference to the disputed objects at all (e.g. Field, 1980; Harman, 1977). But even in such cases, fictionalists are no more likely than other anti-realists to succeed in giving the required accounts. If fictionalists can explain our practices regarding the target objects without assuming the truth of the relevant statements, then so can other anti-realists (and, indeed, realists); but if the assumption of truth is necessary, then fictionalists cannot account for some aspects of our practices.

Meinongianism avoids the weaknesses just observed. Unlike fictionalists, Meinongians take truth in the relevant discourse at face value. They say that the theory we affirm about the objects in question is in fact literally (approximately) true. And, Meinongians apply uniform acceptability conditions to discourse about the target objects and ordinary discourse. In both cases, a statement is acceptable just in case it is thought to be true simpliciter. Moreover, since Meinongians affirm the truth of statements in the relevant discourse, they can appeal to the truth of these statements in accounting for the relevant practices. Therefore, Meinongians are not disadvantaged in the same way as fictionalists compared to other anti-realists. So Meinongianism not only has the strengths of fictionalism, it also avoids fictionalism's weaknesses.

But it should not be inferred from this that Meinongianism is superior to fictionalism. For, Meinongianism has weaknesses of its own, some of which fictionalism avoids. One weakness of Meinongianism lies in its account of reference, which is less straightforward than that given by the realist. In ordinary discourse, our affirmation of a sentence containing a singular term is usually thought to ontologically commit us to the referent of that term. Realists about a kind of object typically affirm this for statements about those objects. 
Meinongians, on the other hand, deny the validity of this inference for the target domain, and thus owe an account of why discourse in this domain is treated differently from ordinary discourse. ${ }^{16}$ Fictionalism avoids this difficulty. Since fictionalists make no distinction between the class of objects that exist and the class of objects to which we can truly ascribe properties, they hold that the truth of $F a$ always implies the existence of the referent of $a$ (though they do not affirm $F a$ whenever $a$ purports reference to one of the target entities). This makes the fictionalist's account of reference uniform between ordinary discourse and discourse about the objects in question. So, it can just as well be said that fictionalism has some of the strengths of Meinongianism without its weaknesses.

What can be said, however, is that Meinongianism presents a viable alternative to fictionalism with reasons in its favour. In light of this, and the fact that the reasons given for fictionalism are often inadequate motivation for the view (as argued in $\$ 3$ ), it might be somewhat surprising that fictionalism is a considerably more popular form of anti-realism than Meinongianism. Perhaps, then, anti-realists in ontological debates ought not be too quick in adopting fictionalism, or in dismissing Meinongianism.

\section{Acknowledgements}

The author would like to thank Mark Colyvan, Kristie Miller, Patrick Dawson, Michael Duncan, Naoyuki Kajimoto, Andrew Latham, James Norton, and two anonymous referees for helpful comments on earlier drafts.

\section{REFERENCES}

Azzouni, J. (2004). Deflating existential consequence. New York: Oxford University Press. Balaguer, M. (1998). Platonism and anti-Platonism in mathematics. New York: Oxford University Press.

Baron, S., Miller, K., \& Tallant, J. (2019). Temporal fictionalism for a timeless world. Philosophy and Phenomenological Research. Advance online publication. doi: https://doi.org/10.1111/phpr.12637

Beall, J. (1999). From full blooded Platonism to really full blooded Platonism. Philosophia Mathematica 7(3), 322-325.

Benacerraf, P. (1965). What numbers could not be. The Philosophical Review 74(1), 47-73.

Benacerraf, P. (1973). Mathematical truth. The Journal of Philosophy 70(19), 661-679.

Benacerraf, P. (1996). What mathematical truth could not be. In A. Morton \& S. P. Stich (eds.). Benacerraf and his critics (pp. 9-59). Oxford: Blackwell Publishers.

Berto, F. (2008). Modal Meinongianism for fictional objects. Metaphysica 9(2), 205-218.

Berto, F. (2011). Modal Meinongianism and fiction: the best of three worlds. Philosophical Studies 152, 313334.

Berto, F. (2013). Existence as a real property: The ontology of Meinongianism. Netherlands: Springer.

Berto, F., \& Priest, G. (2014). Modal Meinongianism and characterisation: Reply to Kroon. Grazer Philosophische Studien 90(1), 183-200.

Brock, S. (2002). Fictionalism about fictional characters. Nồs 36(1), 1-21.

${ }^{16}$ Formally: it is usually thought that $F a \vDash \exists x F x$ holds (in virtue of meaning-see n.10) in ordinary discourse. Therefore, the Meinongian, who claims that there are invalid instances of $F a \vDash \exists x F x$ when $a$ refers to the target objects, owes an account of why this is the case. 
Brock, S. (2015). Fictionalism, fictional characters, and fictionalist inference. In S. Brock \& A. Everett (Eds.). Fictional objects (pp. 231-254). Oxford: Oxford University Press.

Bueno, O. (2009). Mathematical fictionalism. In O. Bueno \& Ø. Linnebo (Eds.). New waves in philosophy of mathematics (pp. 59-79). UK: Palgrave Macmillan.

Bueno, O., \& Zalta, E. (2005). A nominalist's dilemma and its solution. Philosophia Mathematica 13(3), 294-307.

Bueno, O., \& Zalta, E. (2017). Object theory and modal Meinongianism. Australasian Journal of Philosophy 95(4), 761-778.

Burgess, J. P. (1983). Why I am not a nominalist. Notre Dame Journal of Formal Logic 24(1), 93-105.

Burgess, J. P. (2004). Mahematics and Bleak House. Philosophia Mathematica 12(3), 18-36.

Burgess, J. P., \& Rosen, G. A. (1997). A subject with no object: Strategies for nominalistic interpretation of mathematics. Oxford: Clarendon Press.

Castañeda, H. (1972). Thinking and the structure of the world: Discours d'ontologie. Critica: Revista Hispanoamericana de Filosofia 6(18), 43-86.

Castañeda, H. (1975). Identity and sameness. Philosophia 5, 121-150.

Colyvan, M., \& Zalta, E. N. (1998). Mathematics: Truth and fiction?. Philosophia Mathematica 7(3), 336349.

Divers, J. (1999). A modal fictionalist result. Noûs 33(3), 317-346.

Enoch, D. (2011). Taking morality seriously: A defense of robust realism. Oxford: Oxford University Press.

Field, H. (1980). Science without numbers. Oxford: Oxford University Press.

Field, H. (1989). Realism, mathematics and modality. Philosophical Topics 16(1), 57-107.

Harman, G. (1977). The nature of morality. Oxford: Oxford University Press.

Hellman, G. (1989). Mathematics without numbers: Towards a modal-structural interpretation. Oxford: Oxford University Press.

Jacquette, D. (1989). Mally's heresy and the logic of Meinong's object theory. History of Philosophical Logic 10, 1-14.

Jacquette, D. (1996). Meinongian logic: The semantics of existence and nonexistence. Berlin-New York: De Gruyter.

Jacquette, D. (2001). Nuclear and extranuclear properties. In L. Albertazzi \& D. Jacquette (eds.). The school of Alexius Meinong (pp. 397-426). London: Routledge.

Joyce, R. (2001). The myth of morality. New York: Cambridge University Press.

Kalderon, M. E. (2005). Moral fictionalism. Oxford: Oxford University Press.

Kripke, S. (1973). Reference and existence: The John Locke lectures. Oxford: Oxford University Press.

Leng, M. (2005). Revolutionary fictionalism: A call to arms. Philosophia Mathematica 13(3), 277-293.

Leng, M. (2009). “Algebraic” approaches to mathematics. In O. Bueno \& $\varnothing$. Linnebo (eds.). New waves in philosophy of mathematics (pp. 117-134). UK: Palgrave Macmillan.

Leng, M. (2010). Mathematics and reality. Oxford: Oxford University Press.

Leng, M. (2018). Does $2+3=5$ ? In defence of a near absurdity. The Mathematical Intelligencer 40(1), 1417.

Lewis, D. (1978). Truth in fiction. American Philosophical Quarterly 15(1), 37-46.

Liggins, D. (2010). The autism objection to pretence theories. Philosophical Quarterly 60, 764-782.

Linsky, B., \& Zalta, E. N. (1995). Naturalized Platonism versus Platonized naturalism. The Journal of Philosophy $92,525-555$.

Majors, B. (2003). Moral explanation and the special sciences. Philosophical Studies 113, 121-152.

Meinong, A. (1904). Kinds of being. In G. Iseminger (ed.). Logic and philosophy (pp. 116-127). New York: Irvington Publishers.

Nolan, D., Restall, G., \& West, C. (2005). Moral fictionalism versus the rest. Australasian Journal of Philosophy 83(3), 307-330.

Parsons, T. (1978). Nuclear and extranuclear properties, Meinong, and Leibniz. Noûs 12(2), 137-151.

Parsons, T. (1979). The methodology of nonexistence. Journal of Philosophy 76, 649-662. 
Parsons, T. (1980). Nonexistent objects. London: Yale University Press.

Parsons, T. (1982). Are there nonexistent objects?. American Philosophical Quarterly 19(4), 365-371.

Priest, G. (2003). Meinongianism and the philosophy of mathematics. Philosophia Mathematica 11(1), 3-15.

Priest, G. (2005). Towards non-being. Oxford: Oxford University Press.

Putnam, H. (1979). What is mathematical truth?. In Mathematics matter and method (pp. 60-78). Cambridge: Cambridge University Press.

Quine, W. V. (1948). On what there is. The Review of Metaphysics 2(5), 21-38.

Rapaport, W. J. (1978). Meinongian theories and a Russellian paradox. Noûs 12(2), 153-180.

Reynolds, S. (2009). Making up the truth. Pacific Philosophical Quarterly 90, 315-335.

Rosen, G. (1990). Modal fictionalism. Mind 99(395), 327-354.

Rosen, G. (1995). Modal fictionalism fixed. Analysis 55(2), 67-73.

Rosen, G., \& Dorr, C. (2002). Composition as a fiction. In R. M. Gale (ed.). The Blackwell guide to metaphysics (pp. 151-174). New Jersey: Blackwell Publishers.

Routley, R. (1966). Some things do not exist. Notre Dame Journal of Formal Logic 7, 251-276.

Routley, R. (1980). Exploring Meinong's jungle and beyond. Canberra: Australian National University.

Routley, R. (1982). On what there is-not. Philosophy and Phenomenological Research 43, 151-178.

Routley, R. (2003). The importance of nonexistent objects and of intentionality in mathematics. Philosophia Mathematica 11, 20-52.

Russell, B. (1903). Principles of Mathematics. Cambridge: Cambridge University Press.

Russell, B. (1905a). On denoting. Mind 14, 479-493.

Russell, B. (1905b). Review of A. Meinong, Untersuchungen zur Gegenstandtheorie und Psychologie. Mind 14, 530-538.

Russell, B. (1907). Review of A. Meinong, Uber die Stellung der Gegenstandstheorie im System der Wissenschaften. Mind 16, 436-439.

Schaffer, J. (2007). From nihilism to monism. Australasian Journal of Philosophy 85(2), 175-191.

Sendlak, M. (2013). Modal Meinongianism, Russell's paradox, and the language/metalanguage distinction. Polish Journal of Philosophy 7(2), 63-78.

Smart, J. J. C. (1963). Physical objects and physical theories. London: Routledge.

Stanley, J. (2001). Hermeneutic fictionalism. Midwest Studies in Philosophy 25, 72-102.

Sturgeon, N. (1988). Moral explanations. In G. Sayre-McCord (ed.). Essays on moral realism (pp. 229-255). New York: Cornell University Press.

van Fraassen, B. C. (1980). The scientific image. Oxford: Clarendon Press.

Yablo, S. (2005). The myth of the seven. In M. E. Kalderon (ed.). Fictionalism in metaphysics (pp. 88-115). Oxford: Clarendon Press.

Yablo, S. (2009). Must existence questions have answers?. In D. Chalmers, D. Manley, \& R. Wasserman (Eds.). Metametaphysics: New essays on the foundations of ontology (pp. 507-526). Oxford: Oxford University Press.

Zalta, E. (1983). Abstract objects: An introduction to axiomatic metaphysics. Dodrecht: D. Reidel.

Zalta, E. (1988). Intensional logic and metaphysics of intentionality. Massachusetts: MIT Press.

Zalta, E. (2000). The road between pretense theory and abstract object theory. In A. Everett \& T. Hofweber (eds.). Empty names, fiction, and the puzzles of non-existence (pp. 117-147). Stanford: CSLI Publications.

Nathaniel Gan is a graduate student in the Department of Philosophy at the University of Sydney. He received his B.A. in Philosophy from the National University of Singapore. His research interests include the philosophy of mathematics and metaontology.

Address: Department of Philosophy, School of Philosophical and Historical Inquiry, A14 Main Quadrangle, University of Sydney, NSW 2006, Australia. Email: nat_gan@hotmail.com

ORCID: 0000-0002-9463-7955 